\title{
OUTCOME OF PREGNANCY IN ADOLOSCENT AGE GROUP
}

Archana Sudhir $^{1}$, Victor C. Rasquinha ${ }^{2}$, Smitha B. Rao ${ }^{3}$, Rajgopala ${ }^{4}$

\section{HOW TO CITE THIS ARTICLE:}

Archana Sudhir, Victor C. Rasquinha, Smitha B. Rao, Rajgopala. "Outcome of Pregnancy in Adoloscent Age Group". Journal of Evolution of Medical and Dental Sciences 2015; Vol. 4, Issue 43, May 28; Page: : 7483-7488, DOI: $10.14260 /$ jemds/2015/1086

ABSTRACT: INTRODUCTION: Adolescent pregnancy is a common problem encountered in developing countries like India due to early age of marriage. This was seen in women with lower socioeconomic status. Many studies have shown conflicting results. AIM OF THE STUDY: To study the maternal and fetal effects of adolescent pregnancy. MATERIALS AND METHODS: This is a hospital based retrospective study done in Yenepoya Medical College over a period of 18 months. All patients with age between 10-19 years were included. EXCLUSION CRITERIA: Multiple gestation, patients with chronic diseases like, chronic hypertension and diabetes, congenital heart disease and chronic renal disease. RESULTS: Teenage pregnancies are associated with increased incidence of preterm birth, low birth weight babies, delivery by forceps of vacuum, caesarean section and low APGAR at birth. CONCLUSION: Teenage women are more likely to have anaemia, preterm birth, low birth weight babies, delivery by forceps or vacuum or by caesarean section. Good family support, preconceptional counselling, regular antenatal care may improve the perinatal outcome to some extent.

KEYWORDS: Oligohydramnios, Adolescent, Preterm.

INTRODUCTION: Adolescent is a very vulnerable stage both physically and mentally. Adolescent pregnancy is an important health problem as it often occurs in context of poor social support and maternal well being.(1) Adolescence means a transitional stage of physical and mental human development, involving biological, social and psychological changes, occurs between 10-19 years of age ago according to The World Health Organization (WHO). Pregnancy at this period can put an additional strain on this period. The main contributing factors are earlier onset of puberty and early age of marriage.(1)

Studies have shown that there is increased rate of adverse perinatal outcome with teenage pregnancy, which includes pregnancy induced hypertension, preeclampsia, eclampsia, preterm labour, preterm delivery, low birth weight, SGA, low apgar and neonatal mortality with teenage pregnancies.(2)

AIM OF THE STUDY: To study the maternal and fetal effects of pregnancy in adolescent age group.

MATERIALS AND METHODS: A retrospective hospital based study was carried out in the Department of Obstetrics \& Gynaecology of Yenepoya Medical College; a tertiary level health care referral centre in Mangalore, Karnataka over a period of 18months from September 2012 to April 2014.

Inclusion Criteria: All Primigravida with singleton pregnancy aged 10-19 years, gelivering in our hospital within this time period.

Exclusion Criteria: Multiple gestation, patients with chronic diseases like congenital heart disease, chronic renal disease, chronic hypertension and diabetes. 


\section{ORIGINAL ARTICLE}

All selected outcome variables were recorded on printed proforma's in the hospital \& the data was analysed. Findings were analyzed with special emphasis on patient's age, body mass index, maternal outcome \& fetal outcome.

Selected outcome variables included: maternal age, gestational age, antenatal medical complications like anaemia, gestational hypertension, gestational diabetes, amniotic fluid index, mode of delivery, birth weight, congenital anomaly, apgar score \& perinatal mortality. Results were analyzed using percentage \& proportion.

RESULT: 56 teenage deliveries were there in our hospital during this study period. Most of them were 19 years old (89\%), 8.9\% were 18 years old, $1.7 \% 16$ years old.

\begin{tabular}{|c|c|c|}
\hline MATERNAL AGE & NUMBERS & PERCENTAGE \\
\hline 19 & 50 & $89 \%$ \\
\hline 18 & 5 & $8.9 \%$ \\
\hline 17 & 0 & 0 \\
\hline 16 & 1 & $1.7 \%$ \\
\hline & Table 1 \\
\hline
\end{tabular}

Among the patients who were studied most of them delivered at term $(92.8 \%)$, preterm (7.1\%). This suggests that there is slight increase in the incidence of preterm deliveries with decreased maternal age.

\begin{tabular}{|c|c|c|}
\hline Gestational age & Numbers & Percentage \\
\hline 28-34 weeks & 4 & $7.1 \%$ \\
\hline 34-37 weeks & 0 & 0 \\
\hline 37-42 weeks & 52 & $92.8 \%$ \\
\hline \multicolumn{3}{|c|}{ Table 2 } \\
\hline
\end{tabular}

Table 3. Shows that most of the adolescent age group in the study had normal body mass index.

\begin{tabular}{|c|c|c|}
\hline BMI ( WHO) & Number & Percentage \\
\hline$<18.5$ & 7 & $12.5 \%$ \\
\hline $18.5-24.99$ & 45 & $80.3 \%$ \\
\hline $25-29.99$ & 3 & $5.3 \%$ \\
\hline$>30$ & 1 & $1.7 \%$ \\
\hline \multicolumn{3}{|c}{ Table 3 } \\
\hline \multicolumn{3}{|c}{} \\
\hline
\end{tabular}




\section{ORIGINAL ARTICLE}

Table 4 shows that $28.5 \%$ of the study group have anaemia. This table also shows that there is no increased incidence of gestational diabetes, gestational hypertension or placenta previa in adolescent age group. Abnormal presentation included 1 breech and 1 transverse lie. Study shows that there is slight increase in the incidence of oligohydramnios and preterm birth.

\begin{tabular}{|c|c|c|}
\hline Anaemia (Hb $<\mathbf{1 0 g m} \%)$ & $\mathbf{1 6}$ & $\mathbf{2 8 . 5} \%$ \\
\hline Gestational hypertension & 0 & 0 \\
\hline Gestational Diabetes & 0 & 0 \\
\hline Abnormal presentation & 2 & $3.5 \%$ \\
\hline Placenta Previa & 0 & 0 \\
\hline Oligo hydroamnios & 4 & $7.1 \%$ \\
\hline Abruptio placenta & 2 & $3.5 \%$ \\
\hline Preterm & 4 & $7.1 \%$ \\
\hline Table 4 & \\
\hline
\end{tabular}

\begin{tabular}{|c|c|c|}
\hline Mode of delivery & Numbers & Percentage \\
\hline Caesarean section & 19 & $33 \%$ \\
\hline Vaginal delivery & 37 & $66.07 \%$ \\
\hline \multicolumn{3}{|c}{ Table 5 } \\
\hline
\end{tabular}

\begin{tabular}{|c|c|c|}
\hline Assisted Vaginal delivery & Numbers & Percentage \% \\
\hline Vacuum assisted & 4 & $7.1 \%$ \\
\hline Forceps & 2 & $3.5 \%$ \\
\hline Total & $\mathbf{6}$ & $\mathbf{1 0 . 7 1 \%}$ \\
\hline \multicolumn{2}{|c|}{ Table 6} \\
\hline
\end{tabular}

\section{CESAREAN SECTION:}

\section{ELECTIVE LSCS:}

\begin{tabular}{|c|c|c|}
\hline Indication & Numbers & Percentage \\
\hline Fetal distress & 9 & $16 \%$ \\
\hline Abruptio placenta & 2 & $3.5 \%$ \\
\hline Failure of descent in second stage & 1 & $1.7 \%$ \\
\hline Obstructed labour & 1 & $1.7 \%$ \\
\hline Total Table 7 & $\mathbf{1 3}$ & $\mathbf{2 3 \%}$ \\
\hline \multicolumn{2}{r|}{} \\
\hline
\end{tabular}




\section{ELECTIVE LSCS}

\begin{tabular}{|c|c|c|}
\hline Indication & Numbers & Percentage \\
\hline Failed induction & 3 & $5.3 \%$ \\
\hline Cephalo-pelvic disproportion & 1 & $1.7 \%$ \\
\hline Transverse lie & 1 & $1.7 \%$ \\
\hline Previous LSCS & 1 & $1.7 \%$ \\
\hline Total Table 8 & $\mathbf{6}$ & $\mathbf{1 0 . 7 \%}$ \\
\hline \multicolumn{2}{|c}{} \\
\hline
\end{tabular}

Table 5,6,7 and 8 are related to the mode of delivery. This shows that a significant number of them underwent caesarean section i e 33\%. Most of the caesareans were emergency LCSC. (23\%), Most common indication being fetal distress, which constitutes $47.36 \%$ of all LSCS. Out of the 19 LSCS, $68.4 \%$ were done for an emergency indication. This data concludes that there is significant increase in the incidence of emergency LSCS in pregnancies with decreased maternal age. Out of the 43 vaginal deliveries, $74.41 \%$ of them had full term vaginal delivery. 13.9\%were assisted (Vacuum /Forceps), 9.3\%were preterm.

Together this data suggests that there is increased incidence of operative intervention in case of adolescent pregnancies.

\begin{tabular}{|c|c|c|}
\hline Birth weight & Number & Percentage \\
\hline$<2 . \mathrm{kg}$ & 7 & $12.5 \%$ \\
\hline $2.5-3.5 \mathrm{~kg}$ & 46 & $82 \%$ \\
\hline$>3.5 \mathrm{~kg}$ & 3 & $5.3 \%$ \\
\hline \multicolumn{3}{|c|}{ Table 9 } \\
\hline
\end{tabular}

\begin{tabular}{|c|c|c|}
\hline APGAR & $<\mathbf{8}$ in 1 $\mathbf{~ m i n}$ & $<\mathbf{9}$ in 5 min \\
\hline Numbers & 9 & 7 \\
\hline Percentage & $16 \%$ & $12.5 \%$ \\
\hline \multicolumn{3}{|c|}{ Table 10} \\
\hline
\end{tabular}

Table 9 and 10 shows neonatal parameters, that is birth weight and Apgar.

This study showed that $12.5 \%$ were low birth weight babies. $16 \%$ of the babies had low apgar at birth resulting in NICU admission. Perinatal mortality studied in this group showed that there was $1.7 \%$ stillborn and $1.7 \%$ neonatal death.

DISCUSSION: This study was conducted on patients belonging to lower socio economic status who get married at a very young age due to social and cultural factors. All the patients included in my study are married. Studies have shown that there is increased biological risk associated with inadequate control for socioeconomic risk factors.(3) Most of them have a supportive home environment which is essential for an optimal pregnancy outcome.(4,5,6) The main intention of this study is to identify the adverse effects of pregnancy in teenage group, so that we can counsel teenagers preconceptionally regarding contraception and adverse effects of young maternal age. Studies on teenage pregnancies have shown conflicting result. 


\begin{tabular}{|c|c|c|}
\hline Anaemia & $\mathbf{2 8 . 5 \%}$ & $\begin{array}{c}\mathbf{1 8 . 1 \%} \text { sulaiman et al[1] } \\
\mathbf{1 0 \%} \text { ekachai et al[5] }\end{array}$ \\
\hline Preterm & $7.1 \%$ & $\begin{array}{c}24.3 \% \text { sulaiman et al[1] } \\
27.45 \% \text { yasmin et al[3] }\end{array}$ \\
\hline $\begin{array}{c}\text { Oligo } \\
\text { hydramnios }\end{array}$ & $7.1 \%$ & $2.24 \%$ yasmin et al[3] \\
\hline $\begin{array}{c}\text { Gestational hypertension } \\
\text { Gestational } \\
\text { diabetes }\end{array}$ & nil & $\begin{array}{c}0.4 \% \text { ekachai et al[5] } \\
6.4 \% \text { kayasatha et al[6] }\end{array}$ \\
\hline $\begin{array}{c}\text { Abruptio } \\
\text { placenta }\end{array}$ & $3.5 \%$ & $0.3 \%$ ekachai et al[5] \\
\hline
\end{tabular}

\begin{tabular}{|c|c|c|}
\hline Caesarean section & $\mathbf{3 3 \%}$ & $\begin{array}{c}\mathbf{1 9 \%} \text { sulaiman et al } \\
\mathbf{4 . 1 \%} \text { ttlao et al }\end{array}$ \\
\hline Spontaneous vaginal delivery & $55.3 \%$ & $\begin{array}{c}79.4 \% \text { Ttlao et al } \\
89 \% \text { Sulaiman et al }\end{array}$ \\
\hline Low birth weight & $12.5 \%$ & $\begin{array}{c}16.86 \% \text { yasmin et al } \\
17.4 \% \text { ekachai et al }\end{array}$ \\
\hline Low Apgar & $16 \%$ & $2.5 \%$ ekachai et al \\
\hline
\end{tabular}

CONCLUSION: Most of the teenagers are found to be anaemic which increases the morbidity, This is mainly due to the low socioeconomic status. Study concludes that teenagers are at an increased risk of operative delivery, low birth weight and low apgar. Our study shows that there is no significant increase in the incidence of gestational hypertension, diabetes or antepartum hemorrhage in adolescent group. Good family support, pre conceptional counselling regular antenatal care may improve the perinatal outcome to some extent.

\section{REFERENCES:}

1. S Sulaiman, M. B. , MMed (O\&G); S Othman, 2 MBBS, MMed (Family Medicine); N Razali, 1 MBBS, MMed (O\&G); M. J Hassan, et al. (September 2013). "Obstetric and perinatal outcome in teenage pregnancies. " SAJOG Vol. 19( 3): 77-79.

2. Xi Kuan Chen, s. w. w. (2007). "Teenage pregnancy and adverse birth outcomes: a large population based retrospective study. " international journal of epidemiology 36(2): 368-373.

3. Gazala yasmin, a. k. (2014). "Teenage pregnancy - its impact on maternal and fetal outcome. " international journal of scientific society 1(6): 9-13.

4. Martina Derme(1), E. L. , Giuseppe Vetrano(1), Lisa Carlomagno(1), Vincenzo Aleandri (2013). "obstetricc and perinatal outcomes of teenage pregnant women: a retrospective study." Epidemiology Biostatistics and Public Health 10: 8641-8646.

5. Ekachai kovavisarach (2010). "outcome of teenage pregnancy in rajavithi hospital." Journal of medical association thai 93(1): 1-8.

6. Kayasatha s, p. a. (2012). "obstetric outcome of teenage pregnancy" NJOG 7(14): 29-32. 


\section{ORIGINAL ARTICLE}

\section{AUTHORS:}

1. Archana Sudhir

2. Victor C. Rasquinha

3. Smitha B. Rao

4. Rajgopala

\section{PARTICULARS OF CONTRIBUTORS:}

1. Post Graduate Resident, Department of Obstetrics \& Gynaecology, Yenepoya Medical College, Deralakatte, Mangalore.

2. Associate Professor, Department of Obstetrics \& Gynaecology, Yenepoya Medical College, Deralakatte, Mangalore.

3. Assistant Professor, Department of Obstetrics \& Gynaecology, Yenepoya Medical College, Deralakatte, Mangalore.

FINANCIAL OR OTHER COMPETING INTERESTS: None
4. Professor, Department of Obstetrics \& Gynaecology, Yenepoya Medical College, Deralakatte, Mangalore.

\section{NAME ADDRESS EMAIL ID OF THE}

\section{CORRESPONDING AUTHOR:}

Dr. Archana Sudhir, 103, Aysha Residency, Behind Yenepoya Medical College, University Road, Deralakatte, Mangalore-575018, Karnataka.

E-mail: richu1989@gmail.com

Date of Submission: 18/05/2015.

Date of Peer Review: 19/05/2015.

Date of Acceptance: 22/05/2015.

Date of Publishing: 27/05/2015. 